\title{
When Digital Public Spaces Matter. Role of Neighbourhood Platforms in Times of COVID- 19
}

\author{
Franziska Schreiber \\ University of Stuttgart, Department of International Urbanism, Germany \\ franziska.schreiber@si.uni-stuttgart.de
}

\begin{abstract}
Research on community resilience has highlighted the critical role of analogue public spaces for social interaction and community support. However, neighbourhoods are increasingly "hybrid spaces" where face-to-face and virtual interaction blend. Based on the case of Germany, this paper argues that hyperlocal social networks such as digital neighbourhood platforms have taken on a prominent role during the COVID-19 pandemic, as they fulfil functions traditionally associated with analogue public space and provide a useful crisis management tool. They allow communities to share information, establish social contacts, and organize flexible help, which increases their capacity to cope with and adapt to the effects of the pandemic. Yet not everybody has equal access to these digital public spaces and they bear the risk of reinforcing existing social inequalities. In the future, they need to be planned, designed, and managed just as carefully as their physical counterparts to be socially inclusive and serve the common good.
\end{abstract}

Keywords: hyperlocal social networks, social cohesion, digital public space, community resilience, COVID-19

To cite this article:

Schreiber, F. (2020). When Digital Public Spaces Matter. Role of Neighbourhood Platforms in Times of COVID-19, The Journal of Public Space, 5(3), I2I-I30, DOI I0.3289I/jps.v5i3.I368

This article has been double blind peer reviewed and accepted for publication in The Journal of Public Space.

(c) (1) \$ This work is licensed under a Creative Commons Attribution - Non Commercial 4.0 International License https://creativecommons.org/licenses/by-nc/4.0/ 
In 2020, COVID-19 put the world firmly in crisis and literally on hold. In many countries, public life came to a complete standstill: Public institutions such as schools, nurseries, and universities were closed; restaurants and stores shut down; and the use of sports and recreational facilities were prohibited to slow the spread of the virus. In this situation, the immediate neighbourhood became the primary space for action and social interaction as well as the scene of remarkable solidarity and neighbourly help (Schnur, 2020). Virtually overnight, people hung lists in their hallway to organize shopping assistance for neighbours who belonged to a high-risk group; they bought vouchers to support nearby shops or offered to take care of children of "essential workers". This support seems exceptional, but it's actually not. In times of crisis neighbourly aid has always been the norm rather than the exception.

What seems new, however, is the way in which civic engagement and social life in neighbourhoods is being organized and practiced, and with what flexibility and speed. One wonders if and how the growing role of social media and digital communication over the last decade transforms and affects neighbourhood organization in such times of crisis. Nowadays, neighbourhoods increasingly equal "hybrid spaces" (Meine, 2017), where face-to-face and virtual interaction blend: Online-initiated relations require analogue encounters to last, while neighbours who first met analogue now also use messenger services for communication and organisational purposes (Becker, Göppert, Schnur, \& Schreiber, p. 206). In particular, hyperlocal social networks such as digital neighbourhood platforms and local Facebook groups have recently become an important site for social interaction, public debate, and civic engagement and fulfil the functions traditionally associated with public spaces. They allow communities to share (local) information, ask for advice or offer help, connect with others, and encourage identification and a sense of belonging (Schreiber \& Göppert, 2018).

In times of stress and shocks, it is typically the analogue public space that provides a critical infrastructure for communities to establish social contact and organize support, and thereby helps strengthening community resilience (Ley, 2019, p. 168). However, if such space is avoided (or even forbidden to use), digital social networks may constitute alternative spaces that contribute to community-building and crisis management and help make neighbourhoods more resilient. Based on earlier research I have done between $2016-2018$ on various digital neighbourhood platforms in Germany and their contribution to community building, social cohesion and civic engagement (Schreiber \& Göppert, 2018) I seek to propose some first conclusions on their role and meaning in times of crisis. I will do so by focusing on the case of nebenan.de, the largest hyperlocal network in Germany.

\section{The rise of digital networking between neighbours}

Digital neighbourhood platforms are a rather new phenomenon, yet they already show considerable success - even before the COVID-19 pandemic started. Over the past couple of years, hyperlocal social networks such as nextdoor.com (available in different countries), neighbourly.co.nz (New Zealand) or nebenan.de (Germany) emerged around the world. They greatly differ in terms of size, target group and funding structure, but share the same intention of connecting neighbours both online and offline to overcome the widely felt anonymity in larger cities and to ease the exchange of local information and services (Schreiber \& Göppert, 2018). Within the last decade, user numbers on 
such platforms have skyrocketed and challenge the prevailing assumption that many people - especially city dwellers - do not attach great importance to their neighbourhood (Becker et al, 2018).

The world's biggest hyperlocal network nextdoor.com was released in $20 \mathrm{II}$ and is now active in 260,000 neighbourhoods across II countries and has more than 10 million members in the U.S. alone (Kelly, 2020). During the COVID-19 pandemic, such platforms gained further relevance and prominence - both from civil society and policymakers. As soon as the coronavirus outbreak took off, their usage grew rapidly. Nextdoor.com has seen an increase in user activity of up to $80 \%$, especially in severely affected areas such as Seattle and New York City (ibid.). Yet, little is known about the activities that are being organized, by whom, for whom, and with what effect on communities. A closer look at Germany's largest hyperlocal network nebenan.de as an example for the role of such platforms during COVID-19 will help shed some light on this.

\section{The case of nebenan.de: From sharing to solidarity?}

Nebenan.de launched in 2015 and to date counts more than 1,6 million users. It operates as a social business and generates its revenues from voluntary contributions and cooperation with local businesses and city authorities, who pay fees for so-called business or organisational profiles. For private persons, the platform is free of charge. As a registered neighbour, various functions are available including an overview of local businesses, events, and existing neighbourhood groups, a digital marketplace as well as a private chat function and a prominent field for community interaction. What distinguishes nebenan.de from traditional social media is its hyperlocal scope, its 'hybrid' aim of connecting people both digitally and in the analogue realm as well as the higher level of familiarity among users. On the platform, only verified neighbours can become part of the digital community and are required to use their correct name and a photo showing themselves. Moreover, neighbours can only see and communicate with those living in their immediate proximity and in neighbouring areas. These features make interaction much more personal and lower the threshold to get in touch.

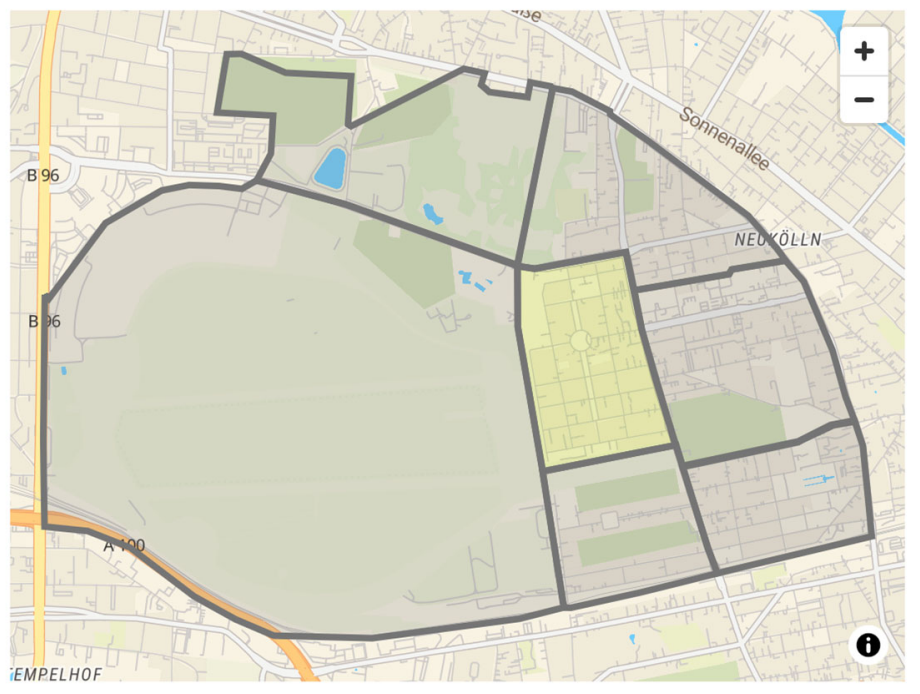

Direkte Nachbarn: 2166 Mit Umgebung: 5592
Figure. I. Screenshot of a digital neighbourhood on nebenan.de and the surrounding areas visible to the registered user. The neighbourhood "Schillerkiez" counts 2166 users whereas the larger area counts 5595 users. (Source: Franziska Schreiber) 
In addition, nebenan.de doesn't apply any algorithms to filter or prioritise content, which leaves the decision up to communities what they consider important and underlines its strict data security policy where no personal data are passed on to third parties (Vollmann, 2018). The combination of the hyperlocal focus and the higher data security of nebenan.de compared to other social media was found to be a major reason for many to revert to the platform in past years.

During the pandemic, user numbers and activities increased significantly on the hyperlocal social network - similarly to other platforms such as nexdoor.com. According to nebenan.de's own data, the number of daily new registrations quadrupled between mid-March 2020 and end-April 2020 and nationwide membership jumped from I,4 million to I,6 million users. In addition, weekly activities of neighbours on the platform increased by $30 \%$.

Yet, it is not only the number of users and activities that are changing, but also the content. In the past, nebenan.de was mainly used in the sense of a sharing economy as well as for community purposes and building new relationships. Neighbours made use of the platform to post classified advertisement and to share and swap things such as drilling machines, rollerblades, kitchen utensils, and many more. The platform also served them to crowdsource and exchange hyperlocal information (e.g., on nearby doctors, good restaurants or recommendable nurseries), and to offer and ask for help related to computer issues, watering flowers or pet sitting. Moreover, neighbours harnessed the digital means to organize community events and to identify and form groups with like-minded people in their immediate proximity. Such neighbourhood groups ranged from people who like to play board games; to cat or dog lovers; to those interested in sustainability issues and keen to initiate projects (Schreiber \& Göppert, 2018).

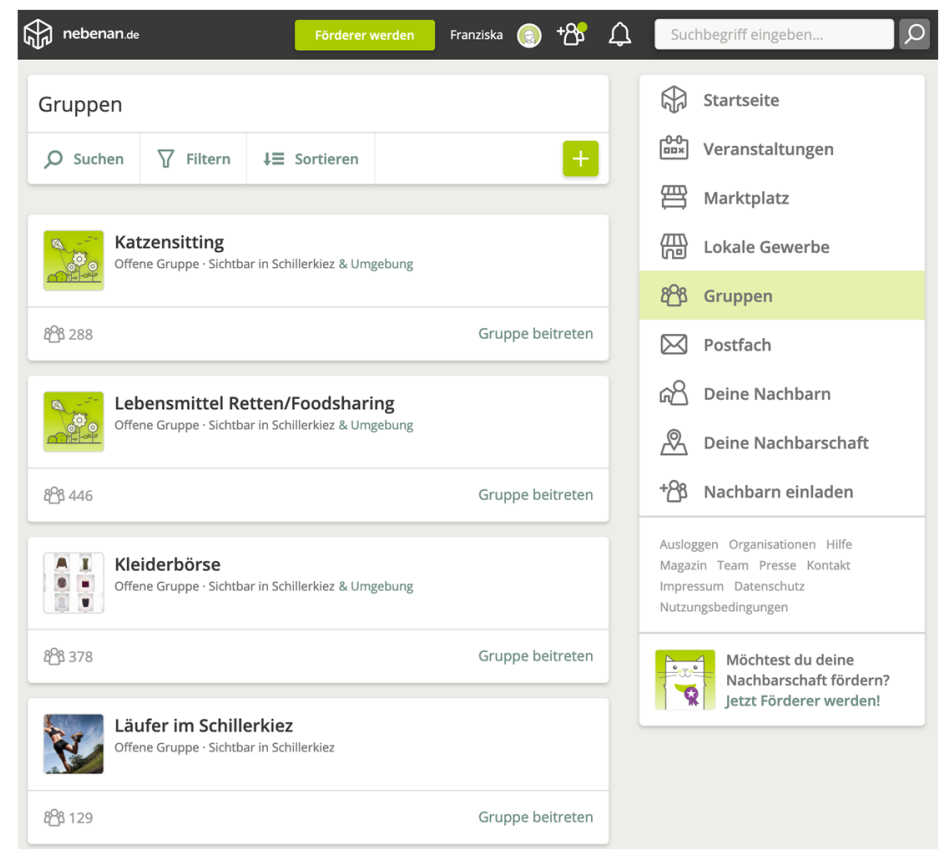

Figure. 2. Screenshot of groups available in a selected digital neighbourhood on nebenan.de. On the right, the functions on the platform are listed including home, events, market place, local businesses, groups, inbox, your neighbours, your neighbourhood and invite neighbours (from the top). On the left, the available groups are shown including cat sitting, food sharing, cloth swapping and a runner's group (from the top). (Source: Franziska Schreiber) 
With the beginning of the pandemic though, the focus changed towards crisis management. All of a sudden, three particular social groups and their needs became the focus of attention and a new set of support activities evolved aimed at helping them in coping with the effects of the coronavirus. Help was offered and organised for vulnerable neighbours (e.g., elderly or those who belong to the high-risk group), for "essential workers" such as doctors, caregivers or cashiers, and families with young children. For vulnerable neighbours, assistance was provided for grocery shopping or walking the dog to protect them from infection, and phone calls were made to counteract social isolation and loneliness. Various solidarity actions were organized for "essential workers" including balcony singing, cooking food or doing the laundry. As soon as schools and day-care-centres closed, help was extended to families and support provided relating to childcare and learning activities (Spiewak, 2020; own observations).

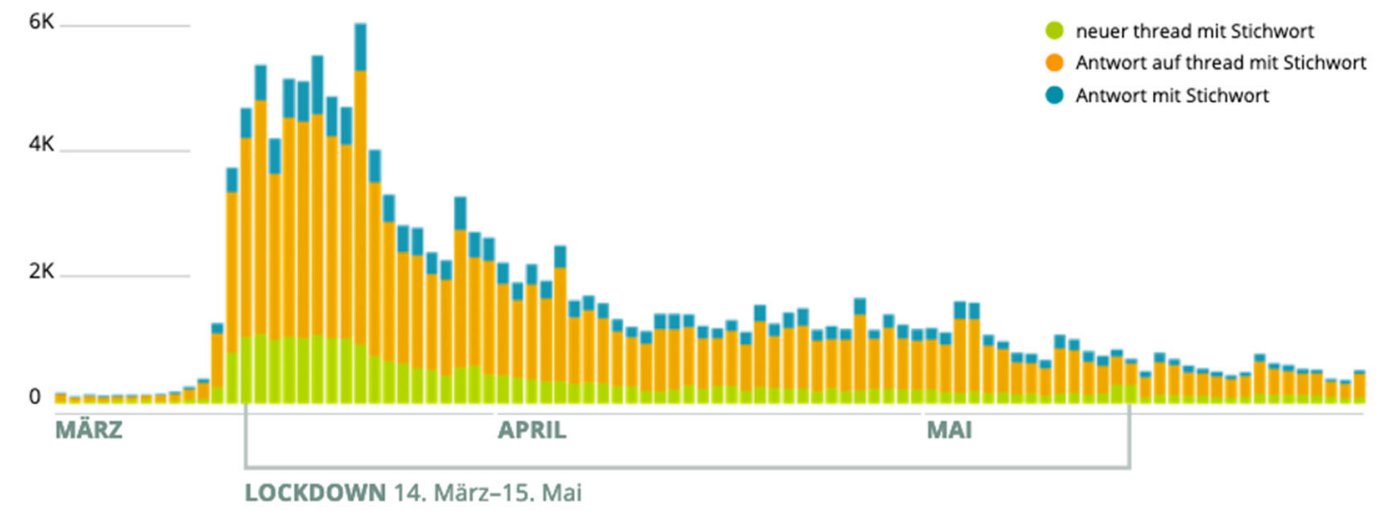

Graph.I. Posts and replies with keywords Corona, Covid, Quarantine from I March to 30 May 2020. Green refers to posts with keywords, orange refers to responses to posts with keyword and blue indicates responses with keywords (Source: nebenan.de)

To reach neighbours in need who were not part of the digital platform, notes were hung in hallways and outside of buildings to inform about possible support. Moreover, nebenan.de quickly expanded its activities by setting up a dedicated Coronavirus help page and hotline to increase its reach beyond the digital community. Between midMarch to the end of July 2020, a total of over 7,600 requests for help were received via the hotline and $85 \%$ of them have been successfully mediated. More than 12.400 neighbours offered their help through this channel, often several neighbours responded to one request for help (nebenan.de, 2020). The platform also started cooperating with various local authorities providing them with the opportunity to directly contact their citizens through the hyperlocal social network to pass on specific Corona-related information (Spiewak, 2020).

We can only speculate whether and how these activities will change further during and after COVID-19. However, previous research on the relationship between digital platforms and civic engagement suggests that most support structures are only occasional and of short duration (Becker et al, 2018). User numbers, in turn, are likely to remain high for the time being thanks to the platform's increased popularity and its engagement during the crisis. What becomes obvious, in turn, is that those, who use 
the platform benefit from crucial support structures and relevant knowledge, which increases their capacity to cope with and adapt to the effects of the pandemic. However, this raises critical questions regarding the accessibility of such platforms and their effects on communities in times of crisis and beyond.

\section{Who benefits and who doesn't?}

No empirical studies have yet been published on the use and implications of such platforms during the COVID-19 pandemic, but we can draw on earlier research analysing their user structures and how they shape public and social life (Schreiber \& Göppert, 2018). In a recent study of four different neighbourhoods in Germany we found that digital platforms expand the local social network of people and increase both their bonding and bridging social capital (Becker et al, 2018). Nearly all users interviewed either met new friends and/or established loose contacts to people of the same and other milieus. The reason is that hyperlocal social networks facilitate neighbourly contact by creating occasions (e.g., lending a drilling machine) and lowering the inhibition threshold of reaching out to others. In this way, they serve as a sort of "introduction service" (Wellman \& Hampton, 1999, p. 652), especially for newcomers to the neighbourhood and those with limited local social capital (Schreiber \& Göppert, 2018). Short encounters through swapping or sharing items or support services convey a sense of mutual helpfulness and local connection that people in larger cities often miss. Such encounters paired with real profile pictures can increase the "public familiarity" (Blokland \& Nast, 20I4) and strengthen a sense of belonging and trust in the neighbourhood. Moreover, hyperlocal social networks ease the crowdsourcing of local knowledge and information and support civic engagement by making existing opportunities visible (Becker et al, 2018, pp. 207-208).

Yet, not all social and age groups use and thus benefit from these platforms equally. It is especially adults between the age of 25 and 70 who use hyperlocal social networks, whereas younger people and senior citizens (above $75+$ ) are hardly reached. The average age with over 40 , however, is significantly higher than that of the average users of social media, which can be explained by the crucial role of the local area for the everyday life of older people (Schreiber \& Göppert, 2018). Young people, in turn, are usually integrated into a dense social network through school and leisure activities and are consequently less dependent on such platforms. Moreover, studies show that they typically revert to other types of social media (MPFS, 2017). In terms of the social status of the users, research suggests that members of the middle class with a high level of education and a modern orientation are overrepresented on digital neighbourhood platforms. This seems to be independent of migration background. However, people with migration background were hardly found on these platforms and seem to be insufficiently addressed by the monolingual offers (Schreiber \& Göppert, 20I8). Initial research also reveals that digital neighbourhood groups are largely formed among people with similar attitudes and social status. In this way, hyperlocal social networks can support mechanisms of social exclusion by intensifying social relations among 'similar' neighbours, whereas people labelled as 'others' according to ethnic and social boundaries are excluded (Becker et al, 2018).

Transferring these results to the context of the pandemic means that with all the euphoria around digital neighbourhood platforms, certain groups and potentially entire 
areas are left out of the neighbourly support networks, both analogue and digital, and end up potentially being doubly disadvantaged (Kurtenbach, 2020). Especially for neighbours of a lower social status and with limited social capital, who might be less able to organise themselves during the COIVD-I 9 crisis, the limited neighbourly support can become an additional disadvantaging factor. Considering the increasing segregation in "affluent" and "poor" neighbourhoods in many cities around the world, this might even be argued for entire neighbourhoods, particularly those that are poverty-stricken (ibid.). Although hyperlocal social networks were found to be used in different types of neighbourhoods in terms of their demographic structure and socioeconomic profile (Schreiber, Becker, Göppert, \& Schnur, 2017), there is still a risk that they may enhance inequality both at individual and neighbourhood scale in the long run. Accordingly, the implications of digital neighbourhood platforms are ambivalent. On the one hand, such platforms can enhance social cohesion and contribute to community resilience, on the other hand, they may reinforce existing social and socio-spatial inequalities and leave those behind, who might need neighbourly support and additional resources the most.

During the pandemic, nebenan.de has tried to expand its reach and diversify addressees by setting up a phone hotline for people less familiar with digital tools. Their requests are sorted by postcode and fed into the respective local neighbourhood network allowing people in the immediate environment to directly contact those needing support (Meinel, 2020). By the end of April more than 6,000 people had used the hotline, mostly elderly or relatives organising assistance for family members - especially concerning shopping assistance and pet care. It is too early to say to what extent this hotline has helped to address the digital divide, but it is certainly a step in the right direction. That it helped closing the social gap is, in turn, rather unlikely.

\section{What can we learn for post-Corona times? Imagining possible futures.}

The COVID-19 pandemic clearly demonstrates the importance of the immediate environment both for crisis management and for social and public life in general, making "“" proximity" the central imperative of the city of the future" (Schneidewind et al, 2020, p.4). Many neighbourhoods in Germany have proven highly resilient in times of COVID19. Community support was organized quickly and flexibly adjusted to the ever-changing situation. This paper shows that hyperlocal social networks played an important role in this. However, we have also seen their limitations in terms of accessibility and inclusivity. Considering that an increasing part of public and social life will likely take place virtually in the future, on digital public spaces such as these platforms, it will be critical to learn from this experience and draw appropriate conclusions. This offers various entry points for both practice and research and to engage with possible futures of these platforms.

- Strengthening recognition as local crisis management tool

The rise in the number of users and activities on hyperlocal social networks during the COVID-19 pandemic offers the potential for harnessing them as dedicated crisis management tool going forward. An increased number of users is now connected and trained in organizing civic engagement and social life in a speedy and flexible manner, should another crisis (of any kind) arise. Integrating these platforms into the "official" crisis management strategies and infrastructures both at local and national level 
promises great benefits. In this context, initial experience in the collaboration between local authorities and platforms such as nebenan.de during the coronavirus crisis should be drawn on and expanded.

- Taking a hybrid approach to the future design of public spaces

Digital neighbourhood platforms have facilitated new social relations and neighbourly support structures, which might persist beyond the pandemic if sufficiently cultivated and supported. However, online-initiated social relations require analogue encounters to last and quality public spaces in the local area where neighbours can meet and mingle and actively engage and shape their environment. Strengthening neighbourhoods thus necessitates taking a hybrid approach to future public space design by thinking both the digital and analogue realm closer together. In addition to investing in well-equipped and modern community centres, this could be ensured through a stronger presence of existing local initiatives and institutions on these platforms to make their often hidden offers visible (Becker et al, 2018). Another pathway could be to create a physical pendant to hyperlocal social networks as done by the initiative Lulu dans ma rue in Paris combining a digital platform with a physical kiosk.

- Harnessing the possibilities of neighbourhood platforms for planning practice Hyperlocal social networks offer important insights into the local needs and sensitivities of citizens and ease communication between neighbours and local authorities as shown during the pandemic (Schreiber \& Göppert, 2018; Spiewak, 2020). Considering the future design of public spaces, utilising such platforms can offer new perspectives for planning practice to engage with citizens and to gain insights into their needs. Here, we can learn from a parallel discourse within planning practice where the potential of 'urban acupuncture' as a new planning approach using digital social networks to involve citizens in hyperlocal placemaking is being explored and shows promising results (Houghton, Foth, \& Miller, 20I5). Further research is, however, needed to understand how to best harness the affordances of such platforms for planners and communities in the future.

- Increasing the inclusivity of digital public spaces

As hyperlocal social networks increasingly fulfil the functions traditionally associated with analogue public spaces, it becomes ever more important to plan, design and manage them just as carefully as their physical counterparts in order to be socially inclusive and to ensure that they serve the common good and not merely private interests. This might involve raising awareness of the availability of such platforms, building digital competencies, ensuring multilingualism and redesigning user interfaces.

Particular attention and support should be given to social groups and types of neighbourhoods, which are not yet embedded in the digital neighbourly support network. To support this, more research is needed on why certain social groups use such hyperlocal social networks, why others don't, and how to make them more accessible in order to counteract social inequalities. This also includes exploring the effects of the hotline set up by nebenan.de during the crisis as supporting element and how it helped close the digital divide.

- Ensuring sustainable financing, provision, and maintenance in the long run The most frequently used platforms such as nebenan.de and nextdoor.com, which assume fundamental (public space) functions for more and more people, are operated commercially and compete around user number. Whether the business model of nebenan.de is viable remains to be seen. However, many other platforms have already 
vanished due to high competition. This raises questions regarding data protection, sustainable financing, provision, and maintenance of such digital infrastructure in the long run, as well as the role and responsibility of the public sector in this regard (Becker et al, 2018, p.210). This necessitates a discussion on potential publicly owned platforms, public-private partnerships as well as open-source platforms as a public good. The variety of these potential roles of hyperlocal social networks for crisis management, public space design and collaborative planning opens up new perspectives for research and practice to build upon to make cities and neighbourhoods more resilient and inclusive going forward.

\section{References}

Becker, A., Göppert, H., Schnur, O., \& Schreiber, F. (20I8). Die digitale Renaissance der Nachbarschaft. Soziale Medien als Instrument postmoderner Nachbarschaftsbildung. Forum Wohnen und Stadtentwicklung, 4, 206-2I.

Blokland, T., \& Nast, J. (2014). From Public Familiarity to Comfort Zone: The Relevance of Absent Ties for Belonging in Berlin's Mixed Neighbourhoods: Belonging in Berlin's Mixed Neighbourhoods. International Journal of Urban and Regional Research, 38(4), I I 42-I I 59.

Houghton, K., Foth, M., \& Miller, E. (20I5). Urban Acupuncture: Hybrid Social and Technological Practices for Hyperlocal Placemaking. Journal of Urban Technology, 22(3), 319.

Kelly, S. M. (2020, May 18). Neighborhood social network Nextdoor is both a lifeline and a hub of anxiety. CNN Business. Retrieved from https://edition.cnn.com/2020/03/18/tech/nextdoorcoronavirus/index.html.

Kurtenbach, S. (2020, April 28). Nachbarschaftshilfe als Zeichen gesellschaftlichen Zusammenhalts. Vielfalt leben - Gesellschaft gestalten. Retrieved from https://blog.vielfaltleben.de/blogger/sebastian-kurtenbach/.

Ley, A. (2019). Community Resilience and Placemaking through Translocal Networking: Learning from Thailand and the Philippines. The Journal of Public Space, 4(2), I65- I 78.

Medienpädagogischer Forschungsverbund Südwest (MPFS.) 20I7. JIM 20 I 7. Jugend, Information, (Multi-) Media. Basisstudie zum Medienumgang 12- bis 19-Jähriger in Deutschland. Stuttgart. Retrieved from https://www.mpfs.de/fileadmin/files/Studien/IIM/2017/JIM_2017.pdf.

Meine, J. (2017). Hybride Sozialräume durch digitale Netzwerkstrukturen im Stadtquartier. In T., Hagemann (Ed.). Forschung und Entwicklung in der Sozialwirtschaft: Band II. Gestaltung des Sozial- und Gesundheitswesens im Zeitalter von Digitalisierung und technischer Assistenz: Veröffentlichung zum zehnjährigen Bestehen der FH der Diakonie (I st ed.). Baden-Baden: Nomos. 
Meinel, H. (2020, May 4). Coronahilfe von nebenan - Das bewirkt die Hotline für Nachbarschaftshilfe. Nebenan Magazin. Retrieved from https://magazin.nebenan.de/artikel/coronahilfe-von-nebenan-das-bewirkt-die-hotline-fuernachbarschaftshilfe.

Nebenan.de (2020). nebenan.de und die Corona-Pandemie. Mit starken Nachbarschaften durch die Krise (Zwischenbericht September 2020). Nebenan.de Retrieved from https://magazin.nebenan.de/assets/downloads/nebenan_corona_report_2020.pdf.

Schneidewind, U., Baedeker, C., Bierwirth, A., Caplan, A., \& Haake, H. (2020). „Näher“„Öffentlicher" - „Agiler“: Eckpfeiler einer resilienten,,Post-Corona-Stadt (Zukunftsimpuls Nr. 14).

Schnur, O. (2020). Kiez und Corona. Nachbarschaft im Krisen-Modus - ein Kommentar. vhw werkSTADT, 40, I-8.

Schreiber, F., \& Göppert, H. (20I8). Wandel von Nachbarschaft in Zeiten digitaler Vernetzung. Vhw-Schriftenreihe, 9, I-44.

Schreiber, F, Becker, A., Göppert, H., \& Schnur, O. (2017). Digital vernetzt und lokal verbunden? Nachbarschaftsplattformen als Potenzial für sozialen Zusammenhalt und Engagement - ein Werkstattbericht. Forum Wohnen und Stadtentwicklung, 4, 2 I I-2 I6.

Spiewak, M. (2020, March I5). In der Krise gewinnt Nachbarschaft neue Bedeutung. ZEIT Online. Retrieved from https://www.zeit.de/gesellschaft/2020-03/nachbarschaftshilfe-nebenan-decoronavirus-sozialleben-ina-remmers.

Vollmann, M. (2018, February 28). Hyperlocal Neighbourhood Networks: Building Social Capital and Empowering Local Urban Communities. Urbanet. Retrieved from https://www.urbanet.info/hyperlocal-neighbourhood-networks/.

Wellman, B., \& Hampton, K. (1999). Living networked on and offline. Contemporary Sociology, 28(6), 648-654. 